\title{
ON INEQUALITIES FOR DIFFERENTIAL OPERATORS
}

\author{
RICHARD BELLMAN
}

Summary. In this paper we study the following problem: Given that certain functionals of $u$ and its derivatives belong to given $\mathrm{L}$ classes over the infinite interval, what can be said about the L-classes of other functionals? Utilizing a simple device from the theory of linear differential equations, we obtain a number of results due to Landau, Kolmogoroff, Halperin-von Neumann, and Nagy, together with some extensions.

1. Introduction. Since the original result of Hadamard concerning a relation between bounds for $u(t), u^{\prime}(t)$ and $u^{\prime \prime}(t)$ for $t$ in a finite interval, a great deal of work has been done in the field of inequalities relating various functionals of $u$ and its derivatives over finite and infinite intervals. A discussion of some questions of this nature may be found in the book by Hardy, Littlewood and Polya, [4], and a collection of more recent results in the appendix to the Russian edition, edited by V. Levin, [8]. For the case where $u(t)$ is an ordinary polynomial, a trigonometric polynomial, or an entire function of exponential type, we refer to the book by Boas, [3].

In this paper we are interested in problems of the following type: Given that certain functionals of $u$ and its derivatives belong to given L-classes over the infinite interval, what can be said about the L-classes of other functionals? Utilizing a method originally sketched in our book on stability theory, $[2$, p. 117], we derive in a uniform fashion a number of results previously obtained by Landau, [7], Kolmogoroff, [6], Halperin-von Neumann, [5], and Nagy, [9], together with some extensions.

Although we do not examine the deeper problem of determining best possible bounds, we shall indicate briefly how the methods we present can be used to obtain inequalities as well as inclusion results.

2. Notation. We shall write $u \in L^{p}$ for the statement that $\int_{0}^{\infty}|u|^{p} d t<\infty$. When the interval is $[-\infty, \infty]$ instead of $[0, \infty]$, we shall write $u \in L^{p}[-\infty, \infty]$. The notation $u \in L^{p}$ with $p=\infty$ means that $|u| \leqq c_{1}<\infty$ for $0 \leqq t<\infty$, or $-\infty<t<\infty$, depending upon the interval under consideration.

3. Some inequalities connecting $u, u^{\prime}$ and $u^{\prime \prime}$. In this section we shall consider inequalities of the type presented by Hadamard,

Received by the editors December 26, 1957 and, in revised form, January 24, 1958. 
Esclangon, Landau, [7], and Kolmogoroff, [6]. The paper by Kolmogoroff contains an account of best possible constants; see also Stein, [10].

We wish to establish the following result: ${ }^{1}$

Theorem 1. If $u \in L^{p}, p \geqq 1, u^{\prime \prime} \in L^{r}, r \geqq 1$, then $u, u^{\prime} \in L^{m}$ for $m \geqq \max [p, r]$.

The two most interesting cases of this result, $p=r=m=\infty$, and $p=r=m=2$, were treated in [2].

Proof. Write

$$
u^{\prime \prime}-u=f+g,
$$

where $f \in L^{r}$ and $g \in L^{p}$. Considering this relation to be a linear differential equation for $u$, with forcing term $f+g$, we can write $u$ in the form

$$
u=c_{1} e^{t}+c_{2} e^{-t}+\frac{1}{2} \int_{0}^{t}\left[e^{(t-s)}-e^{-(t-s)}\right][f(s)+g(s)] d s .
$$

The assumption that $f \in L^{r}$ and $g \in L^{p}$ implies that the integral $\int_{0}^{\infty} e^{-s}[f(s)+g(s)] d s$ converges and that

$$
e^{-t} \int_{0}^{t} e^{s}[f(s)+g(s)] d s
$$

is bounded as $t \rightarrow \infty$. Hence in order that $u \in L^{p}$, it is necessary that

$$
c_{1}+\frac{1}{2} \int_{0}^{\infty} e^{-s}[f(s)+g(s)] d s=0 .
$$

Using this relation, (2) takes the form

$$
u=c_{2} e^{-t}+\frac{e^{t}}{2} \int_{t}^{\infty} e^{-s}[f+g] d s-\frac{e^{-t}}{2} \int_{0}^{t} e^{s}[f+g] d s,
$$

which yields

$$
u^{\prime}=-c_{2} e^{-t}+\frac{e^{t}}{2} \int_{t}^{\infty} e^{-s}[f+g] d s+\frac{e^{-t}}{2} \int_{0}^{t} e^{s}[f+g] d s .
$$

From this representation, we readily derive the stated results. To begin with, consider the case where $m=\infty$. Since, using Hölder's inequality,

1 This is not the best possible result. In private conversation, L. Nirenberg indicated how different arguments can be used to obtain further results. 
1958]

ON INEQUALITIES FOR DIFFERENTIAL OPERATORS

591

(6)

$$
\begin{aligned}
\left|\int_{t}^{\infty} e^{-8} f d s\right| & \leqq\left(\int_{t}^{\infty}|f|^{p} d s\right)^{1 / p}\left(\int_{t}^{\infty} e^{-q z} d s\right)^{1 / q} \\
& \leqq \frac{e^{-t}}{q}\left(\int_{0}^{\infty}|f|^{p} d s\right)^{1 / p},
\end{aligned}
$$

$$
\begin{aligned}
\left|\int_{0}^{t} e^{s} f d s\right| & \leqq\left(\int_{0}^{t} e^{q s} d s\right)^{1 / q}\left(\int_{0}^{t}|f|^{p} d s\right)^{1 / p} \\
& \leqq \frac{e^{t}}{q}\left(\int_{0}^{\infty}|f|^{p} d s\right)^{1 / p},
\end{aligned}
$$

with corresponding results for integrals involving $g$, we see that $|u|$ and $\left|u^{\prime}\right|$ are uniformly bounded for $t \geqq 0$.

If $1 \leqq m<\infty$, we have

$\left|u^{\prime}(t)\right|^{m} \leqq c_{4}(m)\left[e^{-m t}+e^{m t}\left(\int_{t}^{\infty} e^{-s}|f| d s\right)^{m}+e^{m t}\left(\int_{t}^{\infty} e^{-s}|g| d s\right)^{m}\right.$

$$
\left.+e^{-m t}\left(\int_{0}^{t} e^{s}|f| d s\right)^{m}+e^{-m t}\left(\int_{0}^{t} e^{s}|g| d s\right)^{m}\right] \text {. }
$$

Consider a typical term on the right-hand side.

We have

$$
\begin{aligned}
\int_{0}^{\infty} e^{m t}\left(\int_{t}^{\infty} e^{-s}|f| d s\right)^{m} d t \\
\quad \leqq \int_{0}^{\infty} e^{m t}\left(\int_{t}^{\infty} e^{-q s / 2} d s\right)^{m / q}\left(\int_{t}^{\infty} e^{-p s / 2}|f|^{p} d s\right)^{m / q} d t \\
\leqq c_{5} \int_{0}^{\infty} e^{m t / 2}\left(\int_{t}^{\infty} e^{-p s / 2}|f|^{p} d s\right)^{m / p} d t
\end{aligned}
$$

Integrating by parts, we have

$$
\begin{aligned}
\int_{0}^{\infty} e^{m t / 2}\left(\int_{t}^{\infty} e^{-p s / 2}|f|^{p} d s\right)^{m / p} d t \\
=\frac{m}{p} \int_{0}^{\infty} e^{((m-p) / 2) t}|f|^{p}\left(\int_{t}^{\infty} e^{-p s / 2}|f|^{p} d s\right)^{m / p-1} d t \\
\quad \leqq c_{6} \int_{0}^{\infty}|f|^{p}\left(\int_{t}^{\infty}|f|^{p} d s\right)^{m / p-1} d t \\
=\frac{c_{6} p}{m}\left(\int_{0}^{\infty}|f|^{p} d s\right)^{m / p}<\infty
\end{aligned}
$$


We see that the condition that $m \geqq p$ plays an essential role. This completes the proof.

Observe that we have actually established a stronger result than stated. It is not necessary that $u \in L^{p}$ and $u^{\prime \prime} \in L^{r}$, but only that

$$
u=\sum_{k=1}^{N} f_{k}, \quad u^{\prime \prime}=\sum_{k=1}^{N} g_{k}
$$

with $f_{k} \in L^{p_{k}}, g_{k} \in L^{r_{k}}, p_{k}, r_{k} \geqq 1$, and

$$
m \geqq \underset{k}{\operatorname{Max}}\left[p_{k}, r_{k}\right] .
$$

4. Inequalities connecting $u, u^{(k)}$ and $u^{(n)}$. To obtain a corresponding result for a general triplet of derivatives, $u, u^{(k)}$ and $u^{(n)}, n>k>1$, we use the equation

$$
u^{(n)}-u=f+g,
$$

if $n=4 m+2$ or odd, and

$$
u^{(n)}+u=f+g
$$

if $n=4 m$.

The reason for this change of equation lies in our desire to avoid the case where the characteristic equation contains a root with zero real part. The result corresponding to Theorem 1 is

Theorem 2. If $u \in L^{p}, u^{(n)} \in L^{r}, p, r \geqq 1, n>1$, then $u^{(k)} \in L^{m}$ for $m \geqq \operatorname{Max}[p, r]$ and $k=0,1,2, \cdots, n-1$.

The proof follows the same lines as above.

5. Alternative approach for $u, u^{\prime}$ and $u^{\prime \prime}$. If in place of the statement of Theorem 1 we wish to obtain actual inequalities, we can proceed as follows. From the relation

$$
\frac{d}{d t}\left[e^{-t}\left(u^{\prime}+u\right)\right]=e^{-t}\left(u^{\prime \prime}-u\right)
$$

we obtain for $u(t)$ satisfying the hypothesis of Theorem 1 the relation

$$
u^{\prime}=-u-e^{t} \int_{t}^{\infty} e^{-s}\left[u^{\prime \prime}-u\right] d s .
$$

This result is also obtainable from (3.5) upon integrating by parts and observing that $c_{2}=\left[u(0)-u^{\prime}(0)\right] / 2$.

Hence 


$$
\operatorname{Max}_{t \geqq 0}\left|u^{\prime}\right| \leqq 2 \operatorname{Max}_{t \geqq 0}|u|+\operatorname{Max}_{t \geqq 0}\left|u^{\prime \prime}\right| .
$$

Replacing $u(t)$ by $u(r t)$ for $r>0$, we obtain the relation

$$
r \operatorname{Max}_{t \geqq 0}\left|u^{\prime}\right| \leqq 2 \operatorname{Max}_{t \geqq 0}|u|+r^{2} \operatorname{Max}_{t \geqq 0}\left|u^{\prime \prime}\right|,
$$

for $r>0$. From this it follows that

$$
\left(\operatorname{Max}_{t \geqq 0}\left|u^{\prime}\right|\right)^{2} \leqq 8\left(\operatorname{Max}_{t \geqq 0}|u|\right)\left(\operatorname{Max}_{t \geqq 0}\left|u^{\prime \prime}\right|\right) .
$$

Similarly, we can obtain an inequality connecting $\int_{0}^{\infty}\left|u^{\prime}\right|^{m} d t$, $\int_{0}^{\infty}|u|^{p} d t$ and $\int_{0}^{\infty}\left|u^{\prime \prime}\right| r d t$; cf. the arguments given in [1].

Perhaps the easiest way to obtain extensions of the equation in (2) is to use the vector-matrix relation

$$
\frac{d}{d t}\left(e^{A t} x\right)=e^{A t}(A x+\dot{x})
$$

where $x$ is an $n$-dimensional vector, or

$$
x=e^{-A t} \int_{t}^{\infty} e^{A s}(A x+\dot{x}) d s,
$$

for $A$ a stability matrix.

Choosing $A$ suitably, and

$$
x=\left(\begin{array}{l}
u \\
u^{\prime} \\
\vdots \\
u^{(n-1)}
\end{array}\right),
$$

we obtain a variety of relations connecting $u^{(k)}$ with linear combinations of $u$ and the derivatives of $u$. In this way, we can derive a number of extensions of (5).

6. An inequality of Halperin and von Neumann and extensions. An extension of the foregoing techniques yields an extension of the previous results. Let us begin by establishing

Theorem 3. If

$$
\text { a. } u^{\prime \prime}+a_{1}(t) u^{\prime}+a_{2}(t) u \in L^{p}
$$

b. $u \in L^{r}$,

c. $\left|a_{1}(t)\right|,\left|a_{2}(t)\right| \leqq c_{1}<\infty, \quad 0 \leqq t$, 
then $u, u^{\prime} \in L^{m}$ for $m \geqq \operatorname{Max}(r, p)$.

Proof. Let us discuss only the case where $m=\infty$, which means that we are studying the uniform boundedness of $\left|u^{\prime}\right|$. The general case can be treated in the same fashion. In addition to the device we have been using in the previous sections, we must introduce an additional one.

We write

$$
\begin{aligned}
u^{\prime \prime}-M^{2} u & =u^{\prime \prime}+a_{1}(t) u^{\prime}+a_{2}(t) u-\left[a_{1}(t) u^{\prime}+a_{2}(t) u+M^{2} u\right] \\
& =f(t)-a_{1}(t) u^{\prime}
\end{aligned}
$$

where $f(t) \in B[0, \infty]$, by virtue of the assumptions in (1).

Solving for $u$, we write

$$
u=c_{1} e^{-M t}+c_{2} e^{M t}+\frac{1}{2 M} \int_{0}^{t}\left[e^{M(t-s)}-e^{-M(t-s)}\right] f(s) d s
$$

$$
-\frac{1}{2 M} \int_{0}^{t}\left[e^{M(t-s)}-e^{-M(t-s)}\right] a_{1}(s) u^{\prime}(s) d s
$$

Since it is easily established that $\left[u^{\prime \prime}+a_{1}(t) u^{\prime}+a_{2}(t) u\right] \in B[0, \infty]$, $a_{i}(t) \in B[0, \infty], i=1,2$, imply that $\left|u^{\prime}(t)\right| \leqq c_{3} e^{b t}$ for some constants $c_{3}$ and $b$, we see that the integrals $\int_{0}^{\infty} e^{-M s} a_{1}(s) u^{\prime}(s) d s$ and $\int_{0}^{\infty} e^{-M s} f(s) d s$ converge. Consequently (3) has the form

$$
\begin{aligned}
u=c_{1} e^{-M t} & +\frac{1}{2 M} \int_{0}^{t} e^{-M t} e^{M s} f(s) d s \\
& -\frac{1}{2 M} \int_{0}^{t} e^{-M t} e^{M s} a_{1}(s) u^{\prime}(s) d s \\
& +\frac{e^{M t}}{2 M} \int_{t}^{\infty} e^{-M s}\left[f(s)-a_{1}(s) u^{\prime}(s)\right] d s
\end{aligned}
$$

and

$$
\begin{aligned}
u^{\prime}=-M c_{1} e^{-M t} & +\frac{1}{2} \int_{0}^{t} e^{-M t} e^{M s} f(s) d s \\
& -\frac{1}{2} \int_{0}^{t} e^{-M t} e^{M s} a_{1}(s) u^{\prime}(s) d s \\
& +\frac{e^{M t}}{2} \int_{t}^{\infty} e^{-M s}\left[f(s)-a_{1}(s) u^{\prime}(s)\right] d s,
\end{aligned}
$$


From this it follows for an appropriate constant $c_{3}$ that

$$
\left|u^{\prime}\right| \leqq c_{2}\left[e^{-M t}+e^{-M t} \int_{0}^{t} e^{M s}|f(s)| d s+e^{-M t} \int_{0}^{t} e^{M s}\left|u^{\prime}(s)\right| d s\right.
$$

$$
\left.+e^{M \iota} \int_{t}^{\infty} e^{-M s}|f(s)| d s+e^{M t} \int_{t}^{\infty} e^{-M s}\left|u^{\prime}(s)\right| d s\right] \text {. }
$$

Thus, for an appropriate $c_{3}$,

$$
\begin{aligned}
\operatorname{Max}_{0 \leqq t \leqq T}\left|u^{\prime}\right| \leqq c_{3} & +\left(\underset{0 \leqq t \leqq T}{\operatorname{Max}}\left|u^{\prime}\right|\right) / M \\
& +\operatorname{Max}_{0 \leqq t \leqq T}\left(e^{M t} \int_{t}^{\infty} e^{-M_{s}}\left|u^{\prime}(s)\right| d s\right),
\end{aligned}
$$

whence

$$
\operatorname{Max}_{0 \leqq \imath \leqq T}\left|u^{\prime}\right| \leqq c_{3} /(1-1 / M)
$$

$$
+\operatorname{Max}_{0 \leqq t \leqq T}\left(e^{M t} \int_{t}^{\infty} e^{-M s}\left|u^{\prime}(s)\right| d s\right) /(1-1 / M) .
$$

Assuming that $M \geqq 3$, we have

(9) $\quad \operatorname{Max}_{0 \leqq t \leqq T}\left|u^{\prime}\right| \leqq c_{4}+c_{4} \operatorname{Max}_{0 \leqq t \leqq T}\left(e^{M t / 2} \int_{t}^{\infty} e^{-M s / 2}\left|u^{\prime}(s)\right| d s\right)$.

On the other hand, returning to (6) we have

$$
\begin{aligned}
\int_{t}^{\infty} e^{-M t / 2} \mid & u^{\prime}(t) \mid d t \\
\leqq & c_{2}\left[\int_{t}^{\infty} e^{-3 M t / 2} d t+\int_{t}^{\infty} e^{-3 M t / 2}\left(\int_{0}^{t} e^{M s}|f(s)| d s\right) d t\right. \\
& +\int_{t}^{\infty} e^{-3 M t / 2}\left(\int_{0}^{t} e^{M s}\left|u^{\prime}(s)\right| d s\right) d t \\
& +\int_{t}^{\infty} e^{M t / 2}\left(\int_{t}^{\infty} e^{-M s}|f(s)| d s\right) d t \\
& \left.+\int_{t}^{\infty} e^{M t / 2}\left(\int_{t}^{\infty} e^{-M s}\left|u^{\prime}(s)\right| d s\right) d t\right]
\end{aligned}
$$

Integrating by parts we obtain 


$$
\begin{aligned}
\int_{t}^{\infty} e^{-M t / 2}\left|u^{\prime}(t)\right| d t \leqq c_{2}\left[\frac{2}{3 M} e^{-3 M t / 2}\right. \\
\quad+\frac{2}{3 M} e^{-3 . M t / 2} \int_{0}^{t} e^{M s}|f(s)| d s+\frac{2}{3 M} \int_{t}^{\infty} e^{-M s / 2}|f(s)| d s \\
\quad+\frac{2}{3 M} e^{-3 M t / 2} \int_{0}^{t} e^{M s}\left|u^{\prime}(s)\right| d s+\frac{2}{3 M} \int_{t}^{\infty} e^{-M s / 2}\left|u^{\prime}(s)\right| d s \\
\quad+\frac{2 e^{M t / 2}}{M} \int_{t}^{\infty} e^{-M s}|f(s)| d s+\frac{2}{M} \int_{t}^{\infty} e^{-M t / 2}|f(t)| d t \\
\left.+\frac{2}{M} e^{M t / 2} \int_{t}^{\infty} e^{-M s}\left|u^{\prime}(s)\right| d s+\frac{2}{M} \int_{t}^{\infty} e^{-M s / 2}\left|u^{\prime}(s)\right| d s\right]
\end{aligned}
$$

It follows that

$$
e^{M t / 2} \int_{t}^{\infty} e^{-M t / 2}\left|u^{\prime}(t)\right| d t \leqq c_{3}\left[1+\frac{e^{-M t}}{M} \int_{0}^{t} e^{M s}\left|u^{\prime}(s)\right| d s\right]
$$

Hence

$$
\operatorname{Max}_{0 \leqq t \leqq T}\left[e^{M t / 2} \int_{t}^{\infty} e^{-M t / 2}\left|u^{\prime}(t)\right| d t\right] \leqq c_{3}+\frac{1}{M} \operatorname{Max}_{0 \leqq t \leqq T}\left|u^{\prime}(s)\right| .
$$

Combining (8) and (13), we see that $\operatorname{Max}_{0 \leqq t \leq T}\left|u^{\prime}(s)\right|$ is uniformly bounded for $T \geqq 0$. This completes the proof.

The proof of the general result proceeds in analogous fashion.

7. An inequality of Nagy. The following result was obtained by Nagy, [9].

Theorem. If $u \in L^{p}[-\infty, \infty], p>0, u^{\prime} \in L^{r}[-\infty, \infty], r \geqq 1$, then $u \in L^{p+b}[-\infty, \infty]$, for $b \geqq 0$.

In addition, Nagy obtains a much stronger result with best possible constants. Although we cannot establish, using the previous methods, the result in all generality, it is easy to demonstrate the result for $p \geqq 1$. We have

$$
u^{\prime}+u=f+g
$$

where $f \in L^{p}[-\infty, \infty], g \in L^{r}[-\infty, \infty]$. Thus, $u$ must have the form

$$
u=e^{-t} \int_{-\infty}^{t} f(s) e^{s} d s+e^{-t} \int_{-\infty}^{t} g(s) e^{s} d s
$$

The conditions on $f$ and $g$ result in the uniform boundedness of $u$. Hence $u \in L^{p}[-\infty, \infty]$ implies that $u \in L^{p+b}[-\infty, \infty]$ for $b>0$. 


\section{REFERENCES}

1. R. Bellman, An integral inequality, Duke Math. J. vol. 10 (1943) pp. 547-550.

2. - Stability theory of differential equations, New York, McGraw-Hill, 1954.

3. R. P. Boas, Entire functions, New York, Academic Press, 1954.

4. G. H. Hardy, J. E. Littlewood, and G. Polya, Inequalities, Cambridge University Press, 1934.

5. I. Halperin, Closures and adjoints of linear differential operators, Ann. of Math. vol. 38 (1937) pp. 880-919.

6. A. Kolmogoroff, Une generalisation de l'inegalité de $M$. J. Hadamard entre les bornes supérieures des dérivées successive d'une fonction, C. R. Acad. Sci. Paris, vol. 207 (1938) pp. 764-765.

7. E. Landau, Math. Ann. vol. 102 (1929) pp. 177-178.

8. V. Levin, Appendix of Russian edition of the book by Hardy, Littlewood and Polya referred to above.

9. B. Nagy, Uber Integralungleichungen zwischen einer Funktion und ihrer Ableitungen, Acta Sci. Math. Szeged. vol. 10 (1941) pp. 64-74.

10. E. M. Stein, Functions of exponential type, Ann. of Math. vol. 65 (1957) pp. 582-592.

11. I. Halperin and H. R. Pitt, Integral inequalities connected with differential operators, Duke Math. J. vol. 4 (1938) pp. 613-625.

A detailed discussion of inequalities of this type, together with many references, may be found in the expository paper.

A. C. Schaeffer, Inequalities of A. Markoff and S. Bernstein for polynomials and related functions, Bull. Amer. Math. Soc. vol. 47 (1941) pp. 565-579.

The Rand Corporation 